\title{
O MITO E O CONFRONTO CULTURAL N'A GLORIOSA FAMÍLIA DE PEPETELA
}

\author{
Audemaro Taranto Goulart \\ Pontifícia Universidade Católica de Minas Gerais
}

\section{Introdução}

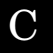

omo reage uma literatura que anda em busca do reconhecimento de

outros povos? Resposta possível, em três tempos: 1) Exibe-se, ao olhar do outro, com aquilo que tem de mais peculiar. 2) Representa-se, perante o estranho, com a mais acesa volúpia de prodígios. 3) Abre o livro de sua história, relendo-a do modo mais crítico possível.

É isso, pode-se dizer, que se encontra no romance $A$ gloriosa família, do angolano Pepetela, narrativa em que brilha o gênio do autor africano. $\mathrm{O}$ romance é um relato longo - 406 páginas - através das quais Pepetela relê um episódio da história angolana, mais precisamente os sete anos (de 1642 a 1648) em que os holandeses, estabelecidos com a Companhia das Índias Ocidentais, realizaram um enorme tráfico de escravos, de Luanda para o Brasil, principalmente. Exatamente por isso, o romance traz como subtítulo “O tempo dos flamengos", numa alusão ao período em que os mafulos nome com que os holandeses eram conhecidos em Angola - dominaram boa parte da região.

E Pepetela faz uma significativa releitura da história angolana, revelando o que há por detrás de episódios que a história tradicional mostrou apenas superficialmente. Para dar um exemplo, pode-se dizer que é esse precisamente o caso da Companhia das Índias Ocidentais, tida como um instrumento de colonização e de aspersão do desenvolvimento cultural, mas que irrompe na narrativa como um empreendimento expansionista do capi- 
talismo europeu, buscando o lucro de seus investidores a qualquer preço. Para conseguir seus objetivos, a violência da Companhia desrespeitava as mais elementares condições dos seres humanos e sua administração movimentava-se num cenário de desmandos, em que atos irresponsáveis, mentiras e interesses escusos se misturavam numa deplorável e obscena realização de desejos de toda sorte.

Buscando, pois, o reconhecimento de sua literatura, Pepetela aciona, além da aludida dimensão ocorrente na releitura da história, as outras duas a que me referi. Para tanto, vai mostrar o que existe de original e de peculiar na gente de África, valorizando as raízes de um povo que é, de modo geral, desvalorizado na história da cultura ocidental e, sobretudo, pondo à mostra o mundo de prodígios que se pode vislumbrar na sua mitologia. E é essa porta - a do universo mítico - que quero abrir, na leitura de $A$ gloriosa familia.

\section{A estrutura mítica}

Para situar minimamente o contexto do livro, diga-se que a gloriosa família que aparece na narrativa é constituída por Baltazar Van Dum e seus onze filhos (três dos quais são resultado de sua união com escravas). Van Dum é uma figura saliente do enredo, encarnando o tipo ladino dos que conseguem agradar a Deus e ao Diabo, pois é um flamengo do sul, mas ligado à religião católica, por ter sido súdito do rei de Espanha. Tais características foram aproveitadas por Baltazar para equilibrar-se entre portugueses e holandeses, à época do domínio que cada um deles exerceu em Angola. Ser flamengo e católico - que esteve a serviço do reino da Espanha - significa uma dupla identidade, a holandesa, por nascimento, e a portuguesa, por afinidade religiosa, e isso propiciou ao esperto Van Dum uma rendosa situação em Luanda, que lhe permitiu enriquecer-se com o tráfico e a venda de escravos.

O cenário angolano em que se desenvolve a narrativa é envolvido por um exuberante componente mítico, de vez que, além dos mitos africanos, que sustentam a história na sua base, a mitologia clássica, a mitologia germânica e histórias extraídas do imaginário popular compõem um grande quadro que intensifica a narrativa ficcional, colaborando para a releitura da história oficial e para validar a visão crítica que perpassa todo o texto. 
O mundo de mitos, de prodígios, de acontecimentos inusitados que constitui a mitologia africana tem presença marcante na estrutura de $A$ gloriosa família. Um do exemplos pode ser encontrado no narrador do romance. Tal narrador - uma das instâncias mais surpreendentes da obra - é um escravo mudo e analfabeto e sua função era a de seguir o patrão, Baltazar Van Dum, a todos os lugares, o que lhe dá a condição de ver e de ouvir tudo aquilo que será matéria de sua narração. Mas uma pergunta poderia ser formulada: como alguém que não fala e que é analfabeto pode ser o sujeito da enunciação de um texto narrativo? É aí que entra o mundo mágico que se estende pelo continente africano. E são os poderes desse mundo que vão dar ao narrador as condições e a confiança para poder contar a história de Baltazar Van Dum e de sua família. $\mathrm{E}$ isso se deve ao fato de que ele usará "poderes desconhecidos dos que se ocultam no pó branco da pemba ou nos riscos traçados nos ares das encruzilhadas pelos espíritos inquietos". Esse prodígio, que revela os ocultos poderes das crenças africanas, projeta-se nos rituais praticados com a pemba, um caulino branco usado nestas cerimônias, sendo de se destacar que a tradição de sua eficiência nas artes da feitiçaria é tão grande que a pemba "acabou por designar o acto do feitiço", como ensina o glossário que acompanha o livro.

Registre-se, ainda, a crença nas mensagens postas nos céus. Já se falou que a profecia feita pela bela feiticeira Matilde, uma das filhas de Van Dum, de que os holandeses ficariam sete anos em Angola, decorreu de mensagem que ela leu, no céu, em letras de fogo. De modo análogo, o narrador também diz dos riscos traçados nos ares pelos espíritos inquietos. Essa ligação com os poderes sobrenaturais, feita através de mensagens no céu, é muito própria dos mitos, pois estes remetem à idéia de que a origem de tudo é sagrada e o caráter transcendente dos céus sempre foi destacado como uma forma de os espíritos superiores entrarem em contato com os humanos. Tal aspecto mostra como os mitos africanos, a exemplo da mitologia clássica, por exemplo, estão inseridos numa ordem que diz respeito a uma espécie de inconsciente coletivo, onde se situam as narrativas arquetípicas, não no sentido de serem matrizes de outras, mas de constituírem uma estrutura que articula as reiteradas relações entre os deuses e os homens.

Não é de estranhar, pois, essa inserção dos mitos africanos no cenário de uma mitologia geral. Lévi-Strauss, uma das maiores autoridades nos estudos do pensamento mítico, lembra que 
tudo pode acontecer num mito; parece que a sucessão dos acontecimentos não está aí sujeita a nenhuma regra lógica ou de continuidade. Qualquer sujeito pode ter um predicado qualquer; toda relação concebível é possível. Contudo, esses mitos, aparentemente arbitrários, se reproduzem com os mesmos caracteres e segundo os mesmos detalhes, nas diversas regiões do mundo. Donde o problema: se o conteúdo do mito é inteiramente contingente, como compreender que, de um canto a outro da terra, os mitos se pareçam tanto? (LÉVI-STRAUSS, 1973. p. 239)

A resposta que Lévi-Strauss oferece à pergunta passa pelo terreno da lingüística, em que se destaca a noção de que a língua se situa num tempo reversível, enquanto a fala se situa num tempo irreversível. Desse modo, a língua e a fala estão inseridas no domínio de sistemas temporais. Lévi-Strauss chama a atenção para o fato de que o mito também se insere em tal sistema, combinando as propriedades tanto da língua quanto da fala. Daí sua afirmação de que

um mito diz respeito, sempre, a acontecimentos passados: "antes da criação do mundo", ou "durante os primeiros tempos", em todo caso, "faz muito tempo". Mas o valor intrínseco atribuído ao mito provém de que estes acontecimentos, que decorrem supostamente em um momento do tempo, formam também uma estrutura permanente. Esta se relaciona simultaneamente ao passado, ao presente e ao futuro. (id., p.241)

Em abono a tais considerações, seria importante acrescentar que os mitos, enquanto forma de explicar a realidade, estão investidos de um caráter racional. Nesse aspecto, pode-se fazer uma aproximação com a filosofia, assinalando que Adorno e Horkheimer entendem que a racionalidade abstrata, fundamento essencial à filosofia, desde os gregos, contém elementos míticos, o que pode ser comprovado com o fato de que a racionalidade filosófica e científica indica que a estrutura do real está ligada a princípios genéricos e universais, o que, em última instância, é também a fundamentação da racionalidade mítica.

Retomando a narrativa de Pepetela, no plano dessa articulação mítica, observa-se que a ligação com os poderes superiores, resultando na capacidade da feitiçaria, explicita-se de modo significativo no episódio em que Angélica Ricos Olhos, mulher de um dos filhos de Baltazar Van Dum, procura vingar-se deste, buscando o auxílio da feiticeira tia Anita. São vários os 
sinais que mostram a surpreendente força do sobrenatural: a jarra que se quebra na mão de Baltazar, a rede que despenca com ele, o estouro do candeeiro, o que faz com que fique irremediavelmente abalada a conviç̧ão de Baltazar quanto à supremacia da religião católica sobre crenças tidas por ele como primitivas e descabidas.

Mas há exemplos em que a referência ao plano do sobrenatural se dá nos limites terrenos. É o caso do mito do leão de cazumbi. Na narrativa, fica-se sabendo desse mito quando Nicolau, um dos filhos de Van Dum, relata um episódio ocorrido na sua volta a Luanda, trazendo mais de cem escravos. À noite, um leão atacou um dos homens, puxando-o pela perna. Coube ao mítico escravo Thor espantar o animal. O que provocou surpresa em todos que ouviam a história foi o fato de o leão haver atacado uma caravana tão grande, que dormia ao pé de várias fogueiras. Coube à mítica Matilde a explicação para a inusitada audácia do animal.

Leão de cazumbi é o pior que existe. Normalmente os leões nem atacam os homens, preferem carne de antílope, bem mais saborosa. E há tantos antílopes e tão poucos homens, nem sei se algum dia será o contrário! Mas o leão de cazumbi é aquele que matou um homem, geralmente porque se sentiu ameaçado. O falecido se torna um fantasma, um cazumbi, porque é vergonhoso ser morto por bicho, qualquer que seja. $\mathrm{E}$ ficar insepulto provoca a errância da alma, inconformada. O cazumbi se vinga, entrando no leão e pondo o animal louco, sem saber medir conseqüências. Chega a atacar as próprias leoas. Mas passa a ter preferência pelos homens e em qualquer circunstância. Se fala de animais que perseguiram colunas de gente durante dias e dias, atacando todas as noites. Como se a banalização das mortes por leão tornasse menor a vergonha do primeiro falecido, do cazumbi. (p. 231)

O que provocou grande surpresa em todos que ouviam o relato foi a circunstância de o leão de cazumbi haver renunciado a novos ataques, depois de espantado por Thor. Entretanto, Matilde avança na explicação.

- Thor deve ter um poder especial que assustou o leão para sempre. Pois ele não voltou a atacar, não é mesmo? Ou um amuleto, ou foi tratado quando era bebé, ou então um dom. Qualquer coisa Thor deve ter. Não é 
normal um leão de cazumbi fugir à primeira tentativa e nunca mais voltar. (p. 231)

Tem-se aí uma intensificação da figura de Thor que é considerado, no nível da enunciação de Matilde, como detentor de poderes superiores, o que faz dele um ser mítico. No nível da enunciação do narrador, a imagem de Thor merecerá um tratamento mítico especial, caracterizando-se como uma das criações mais elaboradas na narrativa. Veja-se que seu nome remete a um deus da mitologia germânica e isso é importante no estabelecimento de contrastes que a narrativa aproveitará, no momento em que proporá questionamentos à pretensa superioridade européia, o que é conseguido com a aproximação contrastiva do escravo com o deus da mitologia germânica, conforme vou mostrar mais detalhadamente no final deste ensaio.

\section{A aproximação com a tradição mítica}

Além dessa aproximação, outras podem ser feitas com figuras da mitologia grega. Para tanto, tome-se a passagem em que Thor é apresentado por Nicolau à família Van Dum. Sua sobranceria, naquele momento, é acentuada pelo narrador ao dizer que "Thor estava na condição de escravo, mas era um homem livre. A liberdade dele estava na maneira como os enfrentava, na língua que humedecia os lábios em sorriso, no olhar insubmisso que mudamente desafiava”. É aqui que percebo uma aproximação com Sísifo, o astuto pai de Ulisses. Uma das maiores artimanhas deste personagem foi a que o trouxe de volta do reino dos mortos. Antes de morrer, Sísifo pediu à mulher que não lhe encomendasse as honras fúnebres. Chegando aos Infernos, foi interrogado por Hades, o deus do mundo subterrâneo, que queria saber porque ele se apresentava sem a vestimenta habitual, ou seja, o corpo. O mais astucioso dos mortais queixou-se amargamente da mulher, que o penalizara negando-lhe os rituais fúnebres, com o que conseguiu a anuência de Hades para voltar à terra e castigar a esposa. Sísifo, na realidade, valeuse do artifício para viver ainda uma longa vida. Mas quando morreu, afinal, os deuses dos infernos lhe impuseram o castigo de ter de rolar um pesado bloco de pedra até o alto de uma montanha. Chegando ao cume, a pedra 
rolava montanha abaixo e Sísifo era obrigado a retomar a subida, permanecendo assim eternamente.

Quero destacar que a aproximação com Thor não se dá no nível da semelhança de ações, mas naquela dimensão que Camus vê no mito grego, dizendo que, por mais paradoxal que possa parecer, o castigo de Sísifo aponta a sua liberdade, na medida em que, aceitando o sofrimento, Sísifo não renuncia à sua condição de desafiante dos deuses e é neste ponto que ele mantém sua superioridade. Não ceder ao castigo, aceitá-lo e pô-lo em prática é, na visão de Camus, usufruir da liberdade que Sísifo se outorga. Aí, se caracteriza, pois, a aproximação com a situação de Thor, um escravo mas também, paradoxalmente, um homem livre, na visão do narrador, pois parecia usar sua condição para desafiar seus senhores, como que afirmando com convicção sua superioridade.

Na citada passagem em que Thor é apresentado à família Van Dum, vejo outro traço que me permite evocar a mitologia clássica. Veja-se como o narrador descreve a sensação que tomou conta de Rosário, outra filha de Baltazar Van Dum, ao deparar o escravo: "E Rosário rendida a tanta liberdade, eu vi, ninguém me contou. Na palidez que sucedeu ao rubor de Rosário, adivinhei drama futuro". Tem-se, aí, uma conjunção intrigante que é a confusão de sensações e sentimentos que tomam conta da filha de Van Dum. De fato, Rosário é levada ao rubor para, em seguida, ser atacada pela palidez, duas reações diferentes que, normalmente, alcançam as pessoas em situações também diferentes. $\mathrm{O}$ rubor diz respeito mais às sensações em que a pessoa fica envergonhada, desconcertada diante de uma situação constrangedora. Já a palidez denota uma reação de desconforto ante um acontecimento que põe a pessoa em risco, antecipando o seu desfalecimento.

Para justificar essa reação de Rosário, e também para explicá-la, veiome à lembrança um verso da Fedra de Racine, justamente na passagem em que Fedra descreve a sua reação diante do enteado Hipólito. Ao ver o jovem, e movida pelas influências traiçoeiras de Afrodite, que queria castigar o filho de Teseu, Fedra afirma: Je le vis, je rougis, je pâlis a sa vie. Neste "eu o vi, enrubesci, empalideci à sua visão", tem-se também uma confusão de sentimentos. E aqui, a explicação está nas ações pérfidas de Afrodite que, não aceitando as inclinações de Hipólito para a deusa Atena, resolve vingarse, fazendo com que Fedra se apaixone pelo filho de seu marido, o que 
termina por levar a desgraça a todos os membros da família. A antecipação do drama futuro já estava, pois, indicada no turbilhão de sentimentos desencontrados que a disputa entre os seres superiores, as duas deusas, provocou em Fedra, uma pobre mortal.

Quero completar o paralelo, dizendo que também no caso de Rosário se dá a intervenção dos seres superiores, levando o escravo à morte, Rosário ao desespero - que se segue, posteriormente, de um alheamento completo diante da vida - e Baltazar Van Dum a uma condição trágica que se vai manifestar, depois, na sua submissão aos poderes da feitiçaria. E tudo isso fora antecipado na pertinente leitura que o narrador fez das reações de Rosário, leitura que o leva a adivinhar o drama futuro.

Como na história de Fedra, tem-se aqui também a presença das forças divinas, e elas aparecem evocadas no nome do escravo. $\mathrm{O}$ que se dá nesse passo é o confronto deuses $\mathrm{x}$ homens, mostrando que o ser humano é, sobretudo, o ser trágico, aquele que se situa na intercessão entre a sua condição de homem e a sua contingência, a sua imperfeição e limitação diante das forças superiores.

É importante lembrar que em $A$ gloriosa família a dimensão mítica espalha-se em várias direções, alcançando outros universos. É o que se tem, por exemplo, com a profecia de Matilde, de que os holandeses permaneceriam em Luanda por sete anos. Na verdade, Pepetela, neste caso, dá um tratamento mítico a um fato histórico, de vez que na página 269 , ao focalizar a figura de Cadornega, ${ }^{1}$ em conversa com Baltazar, em Massangano, vêse o personagem/historiador referindo-se à profecia dos anos de ocupação em Angola, que ele atribui a um jesuíta. E para explicitá-la, ao invés de pôr a personagem falando, a narrativa focaliza o fato, utilizando página da História geral das guerras angolanas:

Lembrava-lhe huma como Profecia predita por hum religioso da Companhia de Jesus, (...) o qual tinha prognosticado, fundado dizião em uma profecia de Esdras, em que sete annos havia de durar o castigo de Deos 
em os Reinos de Angola, e que nenhum Morador dos Antigos viria à terra restaurada nem tornarião à Cidade, seus filhos sim.

(CADORNEGA, 1972, p. 314)

A referência a Esdras, sacerdote descendente de Aarão, doutor nas Leis do Senhor, cujo nome é atribuído a dois livros da Bíblia, já é uma indicação do contorno mítico que se faz presente no texto histórico. E ao escolher a bela Matilde como a adivinha que enxerga o futuro, a narrativa deixa-se imantar do caráter mítico que está presente no terreno da feitiçaria, para associá-lo à dimensão cabalística que o número sete encerra, aproveitando mesmo suas oferendas.

De fato, o número sete insere-se em uma constelação de significações. Chevalier e Gheerbrant, dentre inúmeras outras acepções atribuídas ao algarismo, lembram que o sete

simboliza um ciclo completo, uma perfeição dinâmica. Cada período lunar dura sete dias e os quatro períodos do ciclo lunar $(7 \times 4)$ fecham o ciclo. A esse respeito Fílon observa que a soma dos sete primeiros números (1 $+2+3+4+5+6+7)$ chega ao mesmo total: 28 . O sete indica o sentido de uma mudança depois de um ciclo concluído e de uma renovação positiva. (CHEVALIER \& GHEERBRANT, 1991. p. 826)

Como se pode ver, não é um simples aproveitamento que a narrativa faz do fato histórico para contorná-lo com os traços míticos. Há uma ligação misteriosa do acontecimento com o imponderável, o que dá a ele uma aptidão mítica indiscutível.

Além dessa ligação, o número sete aparece em outras articulações míticas bastante significativas. Ele está em inúmeras manifestações da mitologia grega, como as sete portas de Tebas (que motivou a famosa tragédia de Ésquilo Sete contra Tebas), as sete Hespérides, filhas de Zeus e Têmis, as sete filhas de Níobe, mortas por Ártemis, assim como seus sete filhos, mortos por Apolo, as sete órbitas que constituíam, segundo a astro omia antiga, a morada dos deuses Júpiter, Saturno, Marte, Sol, Vênus, Mercúrio e Lua, o culto de Apolo, cuja celebração se fazia no sétimo dia do mês. 
Nos livros da Bíblia, o sete é muito empregado. Deus criou o mundo em seis dias e no sétimo descansou, o que significa que o sete é o número da conclusão cíclica da criação. A besta do Apocalipse tem sete cabeças e, neste livro, têm-se sete igrejas, sete espíritos de Deus, sete trombetas, sete calamidades, sete reis. Chevalier e Gheerbrant falam ainda: dos sete espíritos repousando na vara de Jessé, dos sete céus onde habitam as ordens angélicas, dos sete anos em que Salomão construiu o templo, da libertação dos servos e da anistia aos endividados a cada sete anos, e do fato de que o sete é usado 77 vezes no Antigo Testamento.

Todas essas manifestações revelam a consistência da dimensão mítica na estruturação da narrativa de $A$ gloriosa família. E tal dimensão pode ser rastreada em outros indícios que a história põe em destaque. É o caso, por exemplo, da situação de Catarina, a filha bastarda de Baltazar Van Dum, que é confinada na cozinha, por determinação de D. Inocência, sua madrasta. Têm-se aí alguns ecos da Gata borralheira, uma história que Perrault fez circular mundo afora mas que é de tradição bem antiga, pois constam registros de sua presença na China, no século IX.

Dois dos elementos desse conto de fadas estão bem representados nas figuras de Catarina, presa ao borralho, e na de D. Inocência, a madrasta cruel. Alguns outros elementos podem ser vistos espalhados pela narrativa, sem se organizarem numa história particular mas agregados a um todo, manifestando-se, pois, como ecos da tradicional história. É o caso, por exemplo, da presença de um príncipe que se anuncia através de uma projeção especular. Trata-se de Rodrigo, outro filho de Baltazar, que se casa com Cristina, filha do Mani-Luanda, uma autêntica "princesa". A união de Rodrigo é vista pela família como um momento glorioso que redimensiona a importância do rapaz, na condição de participante de um clã de grande influência e importância. Vale dizer, Rodrigo como que assume uma posição de príncipe.

Mas a representação da lenda antiga não sobrepaira de modo inocente a narrativa. Ela, de fato, aponta criticamente na direção de situações éticas, morais e religiosas que compõem a tradição familiar, pondo em confronto a situação da obediência a princípios tradicionais e a liberação à fruição do prazer.

Assim, a fada protetora que envolve Cinderela encontra uma dupla representação na narrativa. Matilde, a fada-feiticeira, que assume claramente a proteção da irmã e o próprio narrador, um apaixonado por Catarina, 
que procura protegê-la dos ataques de Redinckove, um poderoso diretor da Companhia, para o que usou de seus poderes feiticeiros. Bastou, pois, que ele atirasse a sua pemba e lá se ia Redinckove de Luanda, chamado de volta pelos seus superiores. Mas a representação da fada protetora da história da Borralheira opera também de forma especular e invertida, na narrativa. De um lado, a protetora Matilde leva a protegida Catarina para o encontro com o seu príncipe encantado. Quer dizer, pela tradição da família e também pela palavra do narrador, a protetora estava, de fato, desencaminhando a protegida, pois a conduzia a um príncipe encantado que era, na verdade, o diretor Redinckove, um vilão na visão do outro protetor, o escravo narrador.

Aí se tem um jogo de reflexos que mistura um mito que desborda de seu nicho para revolver a condição moral da família. Quem protege, desviando, como fez Matilde, leva ao prazer; quem protege, interditando, como fez o narrador, conduz à angústia e à tristeza, pois Catarina sofreu com a partida daquele vilão/príncipe que a fez conhecer o prazer da sexualidade.

Acredito que esse sentido crítico, que é, afinal, a marca mais saliente do livro de Pepetela, não pode ser negligenciado. Se a história da Cinderela é motivo para a visão crítica que acabo de apontar, a conjunção da mitologia africana com a clássica também está eivada desse sentido crítico. Lembro, então, uma passagem em que essa conjunção crítica se dá no plano mesmo do enunciado, o que já é um indicador de que é preciso buscar a dimensão crítica onde ela não se explicita tão claramente, o que, de resto, é uma tarefa para a interpretação do texto. Trata-se do episódio da morte de Sottomayor, governador português, em Massangano, fato que provocou uma série de especulações sobre a causa da morte: febre provocada pelo paludismo? Envenenamento? Obra da feitiçaria, através de uma pemba que lhe mandaram?

Essa última hipótese é que ganha corpo, pois se sabia que "grandes feiticeiros e feiticeiras viviam em Massangano e arredores”. E é aí que se juntavam as bruxarias da África com as que foram trazidas da Europa, numa mistura que punha em polvorosa as autoridades da Inquisiçóo. O mais curioso é que essas autoridades usavam adivinhos na busca dos feiticeiros, conforme diz a narrativa: "Para descobrir um feiticeiro era preciso um adivinho, o qual interpretaria sabiamente as mensagens dos búzios ou dos intestinos de cabrito, como todos sabemos" (p. 290-291). Tem-se, aí, a mistura dos adivinhos e dos feiticeiros, vale dizer, a mistura das mitologias, pois, 
como se sabe, a prática de se examinar as entranhas de animais, em busca da revelação divina, foi introduzida pelos romanos, na sua apropriação da mitologia grega. Enquanto os gregos buscavam o oráculo divino, que era a forma de se ouvir a palavra do deus, a cultura itálica já se inclinava na direção do que tem muito de feitiçaria. Aí se destacavam os arúspices e os áugures, ambos de origem etrusca. Enquanto os primeiros buscavam a mensagem divina no exame das entranhas das vítimas do sacrifício, os segundos procuravam interpretar o vôo dos pássaros e outros sinais do céu, como o relâmpago e os trovões. ${ }^{2}$

É preciso, no entanto, descobrir o sentido crítico que se coloca por trás dessa conjunção da mitologia clássica com a africana. Veja-se que, para encontrar os feiticeiros era necessário contar com os adivinhos e o que mostra como as autoridades religiosas desacreditavam nessas práticas é o fato de que elas "queimavam ambos os suspeitos. Quer dizer, anulava-se a si própria e os feiticeiros riam aos peidos, forma por todos nós conhecida de um feiticeiro demonstrar o máximo júbilo" (p. 291). Assim, fica bem delineada a crítica que é feita à religião como algo que subsiste, não nas suas crenças mas nas suas conveniências.

\section{Um Thor entre o deus e o escravo}

Apontado o modo crítico como a narrativa produz , no nível do enunciado, a aludida conjunção, parto, agora, para a interpretação que procura desenvolver mais um pouco esse aspecto. E essa perspectiva pode ser determinada na figura do escravo Thor, um dos elementos mais importantes da dimensão mítica da narrativa, conforme já havia dito. É óbvio que o nome não é gratuito. A sua escolha tem uma intenção significante que se situa no centro do questionamento feito pelo romance. Qualquer leitor percebe que

2 Lembre-se o Édipo, de Sêneca. Fiel à cultura itálica, o poeta põe Édipo e Creonte diante de Tirésias, na expectativa de que o cego adivinho apontasse quem devia ser castigado pelo crime contra Laio. Tirésias pede que lhe tragam um boi e um bezerro. Em seguida, após Manto colocar incenso no fogo sagrado, pede informações sobre o comportamento da chama assim como do sangue que jorra das vísceras dos animais sacrificados. É por aí, como um arúspice, que ele orienta Édipo sobre como proceder para descobrir a verdade. 
as diferenças entre a figura do deus da mitologia e a do escravo são evidentes. Nesse caso, o que se poderia inferir da aproximação?

Diga-se, inicialmente, que a construção mítica opera num duplo espaço de representação: o contraste e a aproximação. De um lado, tem-se a articulação opositiva, ocorrente no índice de que o nome do escravo remete a um deus da mitologia germânica e só isso já é suficiente para marcar o contraste entre as raças em confronto. A descrição do deus Thor fala por si: “... uma grande barba ruiva pende-lhe sobre o peito, às vezes chamam-no Aquele Que Tem a Barba Ruiva”. Aí está, de modo inequívoco o ariano.

Por outro lado, vai-se perceber o inverso dessa situação contrastiva no momento em que se dá uma aproximação do escravo com o deus da mitologia. A narrativa operacionaliza essa aproximação, fazendo com que o escravo se aproprie de alguns dos atributos do deus. Veja-se, por exemplo, que, na descrição da mitologia, Thor aparece como "um guerreiro grande e muito forte, belo, sempre armado do martelo, o seu emblema; (...) sua voz era estrondosa e penetrante, dos olhos escapavam-se-lhe chispas (SPALDING, 1973. p. 70). Essa descrição lembra alguns detalhes da altaneira figura do Thor escravo, quando foi apresentado à família Van Dum, pintando-o como um cativo diferente, que arranca a admiração e a paixão de Rosário.

Mas é preciso dizer que a narrativa não opera gratuitamente esse jogo de semelhanças e diferenças entre o personagem da ficção e o da mitologia. Nesse sentido, pode-se dizer, em primeiro lugar, que há uma clara intenção de hipertrofiar a figura do escravo para jogar luz na sua situação, agudizando a sensibilidade do leitor na recepção daquele "drama futuro" que o narrador anunciara. $^{3}$

Assim, nesse jogo de embaralhamento das duas figuras, configura-se uma disjunção que tem nítida feição crítica, caracterizada no fato de que se o escravo tem o nome do deus e alguns dos seus atributos, isso deve ser visto muito mais como forma de marcar uma diferença que uma semelhança. No fundo, o que está posto em relevo pela narrativa é uma diferença histórica que envolve culturas distintas em que povos distintos relacionam-se

\footnotetext{
3 Esclareça-se que, no desenrolar da narrativa, “capturado” pela paixão de Rosário, Thor acaba envolvendo-se com ela. Descoberta a relação, o pai da moça, ferido na sua "honra de branco", condena o escravo à morte.
} 
dissimetricamente em termos de poder. Tem-se, pois, uma relação que, aparentemente, trata de uma articulação entre modelo e cópia. Todavia, o que se observa é uma referência irônica a um modelo que só serve para deflagrar um questionamento histórico-político que a narrativa propõe, pondo em xeque o princípio da identidade (ou da semelhança), que é, na verdade, uma espécie de centro iluminador de toda a cultura ocidental, da metafísica que se lança, desde Platão, como instrumento identificador do pensamento filosófico do Ocidente.

O que se tem, portanto, com o livro de Pepetela, é, no plano da identidade, posta em circulação pelos elementos míticos, uma reversão da metafísica ocidental. E tudo isso é sugerido pela presença vigorosa do escravo Thor, na medida em que ele se recusa a ser uma cópia do modelo cultural do Ocidente que se faz representar no deus da mitologia germânica. É de se destacar que esse emblema da identidade africana, que se representa no escravo, recusase a ser qualquer coisa em termos de imitação do modelo que o acompanha através do nome. E ao implodir esse modelo, ele se torna um autêntico simulacro. $\mathrm{Na}$ acepção de Deleuze, é no interior da filosofia platônica que se pode entender bem o simulacro, na medida em que ele é confrontado com a idéia da cópia. Diz Deleuze que as "cópias são possuidoras em segundo lugar, pretendentes bem fundados, garantidos pela semelhança; os simulacros são como os falsos pretendentes, construídos a partir de uma dissimilitude, implicando uma perversão, um desvio essenciais” (DELEUZE, 1974, p. 262). Desse modo, não se deve entender o simulacro como a cópia da cópia mas como uma imagem sem semelhança. Por isso mesmo é que o platonismo sempre esteve interessado em recalcar os simulacros, mantê-los bem no fundo do poço, uma vez que não interessava dar lugar à emergência do desemelhante, do "outro". É preciso ainda dizer que o simulacro contém uma potência positiva que é a de "negar tanto o original como a cópia, tanto o modelo como a reprodução". É por isso que, na articulação que a narrativa estabelece entre o mito germânico e o escravo africano, este só se aproxima do deus da mitologia porque seu interesse é estabelecer a disjunção, a separação completa entre as duas culturas, na busca de afirmar os traços específicos do mundo africano.

E como última palavra sobre a presença da mitologia na narrativa, quero lembrar o que disse no início deste item, destacando a concepção mítica de que a origem de tudo é sagrada o que põe em cena o chamado 
eterno retorno. Para Deleuze, o eterno retorno nada mais é que o caos, uma vez que, à efetiva impossibilidade de retornar o que já foi, o que, verdadeiramente, retorna é o que nunca tinha vindo, ou seja, retorna o que fora recalcado, o que fora impedido de circular, de aparecer. Desse modo, o eterno retorno é a esperança da volta do Mesmo e do Semelhante mas estes, efetivamente, se apresentam na forma do simulacro. Daí Deleuze dizer que o simulacro subverte a representação, destrói os ícones e se ele produz alguma semelhança é a semelhança do desemparelhado.

Dessa forma, se se toma a figura de Thor, vai-se ver que ele é, de fato, o elemento subversivo, detonador das dessemelhanças que afastam um ícone tradicional - a figura do deus da mitologia européia - para alçar-se como uma produtiva presença na narrativa. Pois, agora, pode-se ver, na perspectiva do eterno retorno, que está de volta aquilo que nunca tinha sido: a magnitude do africano, com suas crenças, sua fé num transcendente que se situa muito distante do mundo mítico que a cultura ocidental sempre cultuou com todas as honras.

\section{BIBLIOGRAFIA}

CADORNEGA, António de Oliveira. História geral das guerras angolanas (1680). Lisboa: Agência-Geral do Ultramar, 1972, t. I.

CHEVALIER, Jean e GHEERBRANT, Alain. Dicionário de símbolos. Mitos, sonhos, costumes, gestos, formas, figuras, cores, números. Trad. Vera da Costa e Silva... [et al..], 5. ․ ed., Rio de Janeiro: José Olympio, 1991.

DELEUZE, Gilles. Lógica do sentido. Trad. de Luiz Roberto Salinas Fortes. São Paulo: Perspectiva/Editora da Universidade de São Paulo, 1974.

LÉVI-STRAUSS, C. Antropologia estrutural. Trad. de Chaim Samuel Katz, Rio de Janeiro: Tempo Brasileiro, 1973.ed., Rio de Janeiro: José Olympio, 1991.

PEPETELA. A gloriosa família: o tempo dos flamengos. Rio de Janeiro: Nova Fronteira, 1999.

SPALDING, Tassilo Orpheu. Dicionário das mitologias européias e orientais. S. Paulo: Cultrix/Brasília: INL, 1973. 